\title{
O FINANCIAMENTO DA EDUCAÇÃO BÁSICA NO ESTADO DO ACRE/BR: UM ESTUDO DA VINCULAÇÃO DA RECEITA DE IMPOSTOS
}

\author{
LA FINANCIACIÓN DE LA EDUCACIÓN BÁSICA EN EL ESTADO DE \\ ACRE/BR: UN ESTUDIO DE LA VINCULACIÓN DE LOS INGRESOS FISCALES
}

\author{
THE FINANCING OF BASIC EDUCATION ON ACRE STATE/BR: A \\ STUDY OF INCOMING BINDS
}

\author{
Marcos Edgar BASSI ${ }^{1}$ \\ Pelegrino Santos VERÇOSA ${ }^{2}$
}

RESUMO: O artigo apresenta estudo sobre o financiamento da educação básica da rede de ensino do estado do Acre. Analisa resultados decorrentes da elevação do percentual mínimo de 25 para $30 \%$ de vinculação da receita de impostos estaduais ocorrido em 2000. A análise recorreu a uma revisão da literatura sobre o financiamento da educação e da legislação constitucional estadual do Acre. Os dados, organizados em tabelas, quadros e gráficos em séries históricas, foram extraídos dos balanços gerais de execução orçamentária e de relatórios contábeis de 2001 a 2013 disponíveis em sites oficiais do governo estadual e do Sistema de Informações sobre Orçamentos Públicos em Educação (SIOPE). Evidenciou-se que, dos $5 \%$ acrescidos, apenas meio ponto percentual passou a ser despendido na função educação, elevando para $25,5 \%$ o patamar mínimo para a manutenção e desenvolvimento do ensino. A destinação dos outros $4,5 \%$ pode ser aplicada em despesas não relacionadas diretamente ao ensino.

PALAVRAS-CHAVE: Financiamento da educação. Vinculação da receita de impostos. Manutenção e desenvolvimento do ensino. Educação básica.

RESUMEN: El artículo presenta estudio sobre la financiación de la educación básica del estado de Acre / BR. El estudio analiza los resultados del aumento en el porcentaje mínimo de 25 a 30\% de la vinculación de los ingresos fiscales en 2000. El análisis utilizó una revisión bibliográfica sobre la financiación de la educación y de derecho constitucional del estado de Acre. Los datos organizados en tablas, cuadros y gráficos en series históricas, se extrajeron de las hojas de balance de la ejecución del presupuesto y los informes financieros de 2001 a 2013 disponible en los sitios oficiales del gobierno del estado y el Sistema de Información sobre los Presupuestos Públicos en la Educación (SIOPE). Se demostró que sólo la mitad de un punto porcentual comenzó a ser empleado en la educación elevando a 25,5\% el umbral mínimo para el

1 Universidade Federal de Santa Catarina (UFSC) - Centro de Ciências de Educação. Professor do Departamento de Estudos Especializados em Educação. Doutor em Educação. E-mail: marcos.e.bassi@gmail.com

2 Universidade Federal do Acre (UFA) - Centro de Educação, Letras e Artes. Professor da Área de Educação. Doutor em Educação. E-mail: peleacre@yahoo.com.br 
mantenimiento y desarrollo de la enseñanza. La asignación de otro 4,5\% se puede aplicar con los gastos no directamente relacionados con la enseñanza.

PALAVRAS-CLAVE: Financiación de la educación. Vinculación de los ingresos fiscale. Mantenimiento y desarrollo de la ensiñanza. Educación básica.

ABSTRACT: This article presents a study on the financing of basic educational network system of Acre state. Analyzes results that comes from the elevation of minimum percentual from 25\% to 30\% of the income binds from state taxes run in 2000. The analyses used reviews of educational financing literature and of the Legal Constitution of Acre state. The data, organized in tables, charts and graphics in historical series, were taken from general audits of financing execution and from countable reports from 2001 to 2013 available in oficial estate government websites and in the Information System on Public Financing in Education (SIOPE). It became clear that from the added 5\%, only 0,5\% were really applied in fact on educational purposes, elevating to $25,5 \%$ the minimum pattern to the maintenance and development of teaching. The destination of the remain 4,5\% can be applied in not directly related spendings to the teaching area.

KEYWORDS: Educational financing. Taxes income binds. Maintenance and development of teaching. Basic education.

\section{Introdução}

Em 2000, o governo do Estado do Acre, tendo à frente Jorge Viana, do Partido dos Trabalhadores, implementou uma medida importante no tocante ao financiamento da educação pública. O governo alterou a Constituição Estadual e elevou o percentual mínimo de vinculação da receita de impostos a ser aplicada em Manutenção e Desenvolvimento do Ensino (MDE) de 25 (vinte e cinco) para 30\% (trinta por cento). O fato ganhou repercussão nacional, no setor educacional, principalmente por destoar do contexto de restrição e austeridade fiscal, de inspiração neoliberal, adotado e imposto ao país pelo governo federal, sob a presidência de Fernando Henrique Cardoso.

$\mathrm{O}$ receituário neoliberal adotado naquele período estabeleceu um conjunto de medidas fiscais e de reforma de estado brasileiro que redundou na redução da sua participação na economia, principalmente no financiamento da política social e, consequentemente, na educação pública. Pertence a esse contexto, por exemplo, a implantação do Fundo de Manutenção e Desenvolvimento do Ensino Fundamental e de Valorização do Magistério (Fundef), por meio do qual o governo da União, através de vários mecanismos, "desembarca” do financiamento do ensino fundamental, remetendo essa responsabilidade aos governos estaduais e municipais (OLIVEIRA, 2001). A 
focalização de recursos da vinculação no ensino fundamental deixou em segundo plano o financiamento das outras etapas e modalidades da educação pública. Educação infantil, ensino médio e educação de jovens e adultos passaram a ser financiadas pelas "sobras" da vinculação, dificultando ainda mais a ampliação da sua cobertura escolar.

A iniciativa do governo acreano, na contracorrente do contexto neoliberal predominante, acenou com o aumento dos gastos públicos em educação, indicando, assim, do ponto de vista político, para outra forma de conduzir a política social, na medida em que se propôs a ampliar o papel do estado na garantia do acesso da sua população à educação pública. Contudo, a medida implementada difundiu uma expectativa equivocada na composição do novo percentual, a qual será esclarecida adiante.

Com o objetivo de analisar a alteração na vinculação da receita de impostos para a educação do Governo do Estado do Acre, este texto procura identificar a lógica que norteou aquele procedimento no âmbito da legislação educacional nacional e seu espelhamento na Constituição Estadual do Acre. Ele procurará por em destaque a reformulação ocorrida no início dos anos 2000, ressaltando as peculiaridades que esse mecanismo de financiamento da educação passou a assumir neste estado da federação, diante da formatação estabelecida pela Constituição Federal (BRASIL, 1988) e pela Lei de Diretrizes e Bases da Educação Nacional (BRASIL 1996) para o nível estadual de governo.

A primeira seção recupera a instituição da vinculação nas Constituições Brasileiras e tece considerações sobre os usos e desvios da proposta original da vinculação. A segunda seção detém-se na análise do arranjo estadual acreano e a última é reservada às conclusões. O exercício de análise recorreu a uma revisão da literatura sobre o financiamento da educação e sobre a legislação estadual do Acre correspondente, no contexto em que ocorreu a alteração. Também foram levantados, organizados e analisados dados sobre a execução da vinculação estadual, extraídos de documentos obtidos nas páginas eletrônicas do Governo Estadual do Acre e do Fundo Nacional de Desenvolvimento da Educação (FNDE), na área do Sistema de Informações sobre Orçamentos Públicos em Educação (SIOPE), onde se encontram os demonstrativos de recursos aplicados na educação dos governos.

\section{A vinculação de recursos para educação: aspectos históricos e conceituais}


Conforme José Carlos de Araújo Melchior (1984, pág. 16) a "vinculação constitucional de porcentuais mínimos de dispêndios para a educação é o mecanismo utilizado pelo poder público para garantir uma prioridade permanente para a educação". Na complementação de Romualdo Portela de Oliveira, ela “[...] é a previsão, no texto constitucional, de uma alíquota mínima da receita de impostos a ser aplicada na educação" (2001, 96), cujo sentido é "[...] garantir um mínimo a ser aplicado em educação e induzir um aumento deste montante em relação à média histórica recente" (2001, pág. 99).

A vinculação é, sem dúvida, a medida de maior importância no tema do financiamento da educação (CASTRO, 2001; DAVIES, 2010), expressando a primazia da educação entre as políticas governamentais (OLIVEIRA, 2001). O marco da discussão desse tema remonta ao processo Constituinte de 1933-34, como meio de se garantir a afirmação de direitos educacionais que então se pleiteava (ROCHA, 1996; OLIVEIRA 2001). Sua inscrição na Constituição de 1934 se deve ao empenho dos educadores da Escola Nova. Dessa forma, o poder legislativo à medida que estabelece a legislação que define a vinculação consegue garantir, de forma antecipada, que o poder executivo, independentemente das suas respectivas prioridades, aplique recursos financeiros mínimos em educação.

Cabe ressaltar que a efetivação da vinculação discutida e implementada em um processo constituinte compreende o que Fávero, em estudo acerca da educação nas constituintes brasileiras (2005), atribui aos contextos de democratização e redemocratização brasileiros que os envolve. Nesses períodos, lapsos de tempo em uma cultura política dominada pelo autoritarismo, as pessoas têm a oportunidade de assumir certo protagonismo na produção política e histórica, podendo estes, participar da vida social, como atores ou até mesmo como autores de um processo de construção da constituinte. $\mathrm{O}$ autor destaca que a educação é uma das temáticas mais discutidas na construção das Cartas Magnas, ao qual também se insere os aspectos relacionados ao financiamento da educação.

Tomando por referência estudos sobre o financiamento da educação (DAVIES, 2010; GOMES et al, 2007; OLIVEIRA, 2001; PINTO, ADRIÃO, 2006; SENA, 2002; VELOSO, 1990), identifica-se que a vinculação de receitas tributárias da União, dos Estados e dos Municípios para a educação foi introduzida nas Constituições elaboradas em períodos democráticos e suprimidas nos ditatoriais. Assim, fez-se presente na Constituição Federal (CF) de 1934, quando incorporou parte das ideias presentes no 
Manifesto dos Pioneiros da Educação Nova (O MANIFESTO, 2006), porém esteve ausente na CF outorgada em 1937, período de fechamento democrático no Estado Novo de Getúlio Vargas. É reestabelecida com a CF de 1946, em novo período democrático, mas novamente suprimida na CF de 1967, outorgada pelos militares, durante a ditadura instaurada pelo golpe de estado, em 1964. A vinculação retorna, nesse regime, por meio de emenda constitucional, em 1969, mas valendo apenas como obrigação dos municípios. Em 1983, por meio da Emenda Constitucional n ${ }^{\circ} 24$, popularizada como Emenda Calmon, em homenagem ao senador João Calmon, ela é reintroduzida na CF então em vigor. A medida passou a ser cumprida efetivamente apenas a partir de 1985, quando a União se viu comprometida a aplicar no mínimo $13 \%$ da sua receita de impostos, enquanto os estados, e Distrito Federal e os municípios, $25 \%$.

A vinculação atualmente em vigência encontra-se declarada no Artigo 212 da Constituição Federal de 1988 (CF88), consolidando a que foi reintroduzida na Constituição anterior, com a diferença de que, no processo Constituinte, o percentual incidente sobre a receita de impostos especificamente da União foi elevado para 18\%:

Art. 212.A União aplicará, anualmente, nunca menos de dezoito, e os Estados, o Distrito Federal e os Municípios vinte e cinco por cento, no mínimo, da receita resultante de impostos, compreendida a proveniente de transferências, na manutenção e desenvolvimento do ensino. (BRASIL, 1988, grifos nossos).

Esse movimento pendular da vinculação nas constituições (GOMES et al, 2007) entre os períodos autoritários, quando era suprimida, e os democráticos no Brasil, quando era retomada, mostra o esforço em se proteger os recursos do arbítrio dos governantes. De fato, como destaca Oliveira (1995), tendo por referência estudo de José Carlos de Araújo Melchior (1984), os aportes de recursos cresceram, nos períodos em que a vinculação se encontrava consagrada em lei e diminuíram, quando não.

Castro confirma a vinculação como mecanismo de proteção à área da educação, na medida em que tem garantido um mínimo de recursos nos períodos em que prevalecem graves crises econômicas e decorrentes cortes orçamentários $(2001 ; 2007)$.

Todavia, essa proteção somente se efetiva na medida em que a vinculação constitucional requereu juntamente com a Emenda Calmon a "precisa definição de despesas em educação" (OLIVEIRA, CATANI, 1993). À época, a vinculação foi regulamentada pela lei $\mathrm{n}^{\text {o }}$ 7.348, em 1985 (BRASIL, 1985). Nos marcos estabelecidos pela CF88, a destinação da vinculação só seria adequadamente regulamentada, em 1996, 
nos artigos n. ${ }^{\text {os }} 70$ e 71 , da Lei de Diretrizes e Bases da Educação Nacional (LDB) (BRASIL, 1996a). Esses artigos procuram delimitar com maior precisão a aplicação das receitas vinculadas em manutenção e desenvolvimento do ensino, ou seja, em “[...] despesas realizadas com vistas à consecução dos objetivos básicos das instituições educacionais de todos os níveis [...]" (BRASIL, 1996, artigo 70, caput). Nesse sentido, essa legislação também procura preservar a destinação da vinculação a despesas decorrentes de interpretações mais forçosas, abrangentes e oportunistas quanto a gastos estranhos ao campo educacionais.

O texto constitucional, como salienta Amaral (2012), estabeleceu somente o piso dos percentuais mínimos que deveriam ser aplicados em MDE. Nesse sentido, os Estados e os Municípios brasileiros, através de suas legislações correspondentes, poderiam promover mudanças nesse percentual, podendo aumentar os percentuais mínimos.

As constituições estaduais e a leis orgânicas municipais, elaboradas e aprovadas na esteira da promulgação da CF88 (BRASIL 1988, artigo 25 e artigo 11 do ADCT), transpuseram a temática educacional em seus textos. No caso mais específico da vinculação na legislação estadual, por onde orbita o campo de estudo deste artigo, Oliveira e Catani (1993) identificaram variações importantes nas alíquotas, a despeito da maioria dos estados ter reproduzido o que fora prescrito na Carta Magna:

\footnotetext{
Vincularam 30\% da receita de impostos, os estados de Goiás (artigo 158), Mato Grosso do Sul (artigo 198), Piauí (artigo 223) e São Paulo (artigo 255), e 35\% no Mato Grosso (artigo 245), Rio Grande do Sul (artigo 202) e Rio de Janeiro (artigo311). (OLIVEIRA, CATANI, 1993, p. 34).
}

A atual LDB ratificou essa formulação ao acrescentar, no artigo que reproduz os termos da vinculação no texto constitucional a frase, "ou o que consta nas Constituições ou Leis Orgânicas” (BRASIL, 1996a, artigo 69). Contudo, a concretização desse adicional em recursos para a educação, desde então, tem se tornado uma questão em disputa, ao sabor do contexto político e econômico em torno da partilha e do destino do orçamento público.

Em anos recentes, muitos dos Estados e Municípios que declararam em sua legislação constitucional alíquotas superiores ao da CF88 ou as reduziram ao mínimo constitucional federal ou, respaldados por decisão judicial, deixaram de cumpri-las. Entre aqueles estados mencionados por Oliveira e Catani, exemplificam a primeira 
situação os estados do Mato Grosso do Sul e de Goiás. No primeiro estado, a nova redação do artigo 198 alterada em 1997 simplesmente declara que a manutenção e desenvolvimento do ensino "[...] far-se-á mediante a aplicação dos dispositivos contidos na Constituição Federal” (MATO GROSSO DO SUL, 1989). No Estado de Goiás, ainda que a alíquota tenha sido reduzida para 28\%, em 2003, a redação do artigo declara que $25 \%$ da receita se destinam à manutenção e ao desenvolvimento do ensino, enquanto os $3 \%$ restantes, para a política de ciência e tecnologia e para a educação superior estadual ${ }^{3}$ (GOIÁS, 1989, artigo 158). A segunda situação é exemplificada pelo Estado do Rio de Janeiro que, por meio de uma decisão liminar do Supremo Tribunal Federal, desobrigou-se de aplicar o percentual inscrito na Constituição Estadual, limitando-se, a partir de então, ao patamar da CF88 (DAVIES, 2004a).

Os estudos sobre o financiamento da educação que abordam a vinculação têm constatado uma série de irregularidades, ilegalidades e usos indevidos e até abusivos em sua aplicação pelos governos, bem como fragilidades, inconsistências e pouca eficácia na fiscalização por parte dos órgãos responsáveis pelo controle da administração pública e cumprimento das normas legais de execução orçamentária. O resultado disso é a má aplicação, a má gestão e o desvio dos recursos da vinculação, contribuindo para a penúria e precarização das condições de qualidade da escola pública e a negação do direito da população brasileira à educação.

As análises realizadas por Nicholas Davies sobre a atuação dos Tribunais de Contas (TCs) da União e dos Estados na fiscalização dos recursos têm sido fundamentais na identificação do descumprimento da vinculação. A lista de irregularidades e ilegalidades é longa, a começar pelo não cumprimento pelos governos das verbas para educação; a identificação de grosseiras falhas técnicas nos pareceres dos TCs; as diferentes interpretações sobre o cálculo das receitas e despesas de MDE dados pelos TCs; a inclusão das aposentadorias na base de cálculo da vinculação; vários TCs não seguem as disposições legais; não exigência do cumprimento dos percentuais acima do mínimo constitucional federal; aprovação pelos TCs de contas governamentais abaixo do mínimo constitucional; dentre tantas outras. Além desses órgãos, o autor acrescenta que o Ministério Público também não tem zelado pelo cumprimento da legislação referente ao financiamento da educação. (DAVIES, 1999; 2000; 2004b; 2006; 2007, 2010; 2011; 2012; 2015).

${ }^{3}$ Em 2005, nova alteração é introduzida na constituição estadual elevando ligeiramente a vinculação para 28,25\%, mas mantendo a aplicação em MDE em 25\%. (GOIAS, 2005, artigo 158). 
Nesse âmbito, as alterações promovidas pela Prefeitura do Município de São Paulo (PMSP) na vinculação dos seus recursos para a educação são de particular interesse aos objetivos deste artigo, já que ocorreram no mesmo contexto histórico, apresentaram semelhanças na natureza das alterações e foram conduzidas por iniciativa do mesmo partido político à frente do governo. Em 2001, o governo municipal aprovou a elevação do percentual de vinculação de $30 \%$ (trinta por cento) aplicados em despesas de MDE, vigente desde 1992, para 31\% (trinta e um por cento). Porém, 6\% (seis por cento) da nova alíquota foram desvinculados de MDE e subvinculados a programas e despesas assistenciais, culturais e esportivas que não se relacionam ao processo de ensino, embora o governo paulistano insistisse no seu vínculo educacional, ao nomeá-la educação inclusiva (BASSI, 2011). A alteração consolidou o não cumprimento da vinculação inicialmente instituída, em três oportunidades, em governos anteriores de filiação político partidária conservadora, sem que, nesse caso, a demanda por educação infantil, responsabilidade legal dos municípios, afeita ao campo de MDE, houvesse sido atendida.

A alteração da alíquota da vinculação providenciada na constituição estadual do Acre, analisada na próxima seção, enquadra-se nessa última perspectiva.

\section{A vinculação de receitas para a educação no contexto da legislação do estado do Acre}

No estado do Acre, a vinculação de recursos para a educação está definida no artigo 197 da Constituição Estadual, promulgada em 1989. O texto estadual transpôs a essência e o percentual mínimo estabelecido no Art. 212 da CF88 (ACRE, 1989), ao definir a vinculação de um mínimo de $25 \%$ (vinte e cinco por cento) da receita de impostos e transferência para MDE. Na redação do artigo, curiosamente, a Constituição Estadual determinou e circunscreveu o mesmo percentual de aplicação para os seus municípios. Tal acréscimo foi no mínimo desnecessário, na medida em que a determinação constitucional já estava prevista no Art. 212.

Em 2000, o governo estadual, por intermédio da Lei no 20 (ACRE, 2000), promoveu alterações no caput do artigo e acrescentou dois parágrafos com especificações (Quadro 1). 
Quadro 1: Vinculação da receita de impostos e transferências em manutenção e desenvolvimento do ensino e em educação, conforme o artigo $n^{\circ} 197$ da Constituição do Estado do Acre de 1989 e Emenda no 20/2000.

\begin{tabular}{|c|c|}
\hline Redação original & $\begin{array}{cccc}\text { Redação } & \text { dada } & \text { pela } & \text { Emenda } \\
\text { Constitucional no } & \text { 20/2000 }\end{array}$ \\
\hline $\begin{array}{l}\text { O Estado e os Municípios aplicarão, } \\
\text { anualmente, nunca menos de vinte e cinco } \\
\text { por cento da receita resultante de impostos, } \\
\text { inclusive a proveniente de transferência, na } \\
\text { manutenção e desenvolvimento do ensino. }\end{array}$ & $\begin{array}{l}\text { O Estado do Acre aplicará, } \\
\text { anualmente, com a educação, nunca menos de } \\
\text { trinta por cento da receita resultante de } \\
\text { impostos, inclusive a proveniente de } \\
\text { transferências constitucionais da União. } \\
\qquad 1^{\circ} \text { Oitenta e cinco por cento dos } \\
\text { recursos de que trata este artigo serão } \\
\text { destinados à manutenção e desenvolvimento } \\
\text { do ensino. } \\
\qquad 2^{\circ} \text { A ampliação dos investimentos } \\
\text { na educação, prevista no caput deste artigo, } \\
\text { deverá ser alcançada no prazo de três anos, } \\
\text { considerando o exercício de } 2001 \text {, à razão de } \\
\text { um por cento ao ano, observado o disposto no } \\
\text { art. } 205 \text { da Constituição Federal. } \\
\text { [...]. }\end{array}$ \\
\hline
\end{tabular}

Fonte: Elaborado com base em ACRE (1989; 2000, grifos nossos).

A nova redação passou, então, a estabelecer, como percentual mínimo de vinculação, 30\% (trinta por cento) da receita dos impostos e transferência constitucionais, porém não mais para despesas estritamente consideradas de manutenção e desenvolvimento do ensino (MDE). A substituição da expressão MDE por Educação permitirá a reinterpretação do destino e da abrangência dos recursos da vinculação. $\mathrm{O}$ texto também corrigiu e exclui a menção aos municípios.

Diante do quadro construído por mudanças na Constituição Estadual do Acre, há de se buscar compreender a lógica implementada pela Lei no 20/2000 no que se refere ao novo percentual. O que aparentemente seria um ganho para a expansão da escola foi diluído nas especificações. Senão, vejamos. O $\S 1^{\circ}$ estabelece que $85 \%$ (oitenta por cento) do novo patamar mínimo ( $85 \%$ de $30 \%$ ) devem ser destinados à MDE, o que equivale a $25,5 \%$ (vinte e cinco e meio por cento), portanto meio ponto percentual acima do vínculo original. Sendo que no $\S 2^{\circ}$ ficou definido que, no prazo de 
três anos, esse aumento deva ser consolidado, considerando a contagem a partir de 2001. A respeito desse dispositivo, existe uma incongruência, pois se o prazo definido para se chegar a $30 \%$ é de três anos e o crescimento anual previsto é $1 \%$ (um por cento) ao ano, essa proporção não seria suficiente para se chegar à meta.

O texto da lei não define e nem menciona qual o destino dos $4,5 \%$ (quatro e meio por cento) restantes. Dessa maneira, o governo estadual passou a dispor desse percentual a mais de receita para aplicar da forma que lhe parecesse mais conveniente na rubrica mais ampla da educação. Considere-se que não foi encontrada lei estadual que regulamentasse a aplicação desse percentual adicional. Nem mesmo consulta à página eletrônica do Tribunal de Contas do Estado do Acre (TCE/AC) encontrou qualquer norma que regulamentasse a fiscalização da nova formulação. O TCE/AC dispõe de uma resolução, publicada no mesmo ano da alteração da Constituição Estadual, que regulamenta apenas o cumprimento das alterações nacionalmente introduzidas pela Emenda Constitucional 14/96; portanto limita-se à fiscalização do cumprimento do patamar de vinculação da CF88 e das subvinculações relativas ao Fundef pelo governo estadual e pelos municípios (TRIBUNAL, 2000).

A despeito da ausência de regulamentação legal, os argumentos elaborados e utilizados pela equipe de governo para justificar o que poderia ser considerado como gasto em educação é encontrado em um dos anexos do Balanço Geral do Acre, a partir de 2006, repetido com irrelevantes alterações nos seguintes termos:

O Estado vem cumprindo com esses dispositivos no que se refere aos investimentos destinados à manutenção e desenvolvimento do ensino. Contudo, há necessidade de se definir a aplicação da diferença entre os $30 \%$ estabelecidos no caput do Art. 197 da CE e os valores aplicados no [sic] MDE (25,5\%), onde esta diferença (4,5\%) deverá ser sustentada pela definição de educação constante no Art. 205 da CF [sic]. (ACRE, 2006, p. 23, grifos nossos).

O que se procura evidencia na mudança do percentual da vinculação de receitas da educação no âmbito do estado do Acre, é uma tentativa de justificar a utilização da diferença de 4,5\% sob a ótica do artigo 205 da CF/88, que contempla uma definição genérica do sentido da educação:

[...] a educação, direito de todos e dever do Estado e da família, será promovida e incentivada com a colaboração da sociedade, visando ao pleno desenvolvimento da pessoa, seu preparo para o exercício da cidadania e sua qualificação para o trabalho. (ACRE, 2006, p. 23) 
A argumentação faz referência ao artigo $n^{\circ} 188$ da Constituição Estadual e ao artigo $2^{\circ}$ da LDB, que estabelecem os mesmos preceitos. Porém, como esclarece Cury (2008), a definição contida nesse preceito deve ser compreendida e reforçada, de modo abrangente, como um direito social das pessoas, do qual elas devem usufruir; cabendo ao Estado a sua respectiva implementação e efetivação, como também, não se desobriga da participação de outros agentes, como a família, e outras instituições da sociedade.

O texto ocupa mais 3 (três) páginas com argumentos sociológicos e pedagógicos, estranhos a um instrumento técnico contábil de prestação de contas do governo. Ele prossegue descrevendo o que se entende por gastos com educação: as despesas de MDE propriamente ditas ao lado das despesas cabíveis em funções administrativas da contabilidade pública (Cultura, Ciência e Tecnologia, Assistência social, Agricultura e Desporto e Lazer), sem mencionar a função Educação. Assim, a vinculação consagrada com a proteção de uma parcela da receita de impostos destinada ao ensino é confundida com a forma de contabilização as despesas públicas (MELCHIOR, 1984).

Pelo que se identifica nesse documento, o governo do estado utilizava essas outras funções para justificar o uso dos recursos da vinculação no que não são definidos como MDE. Dessa forma, o que poderia representar ganho para educação estadual, na verdade perde-se nas estratégias do governo ao mobilizar recursos para outros segmentos da administração pública.

O Gráfico 1 apresenta uma série histórica dos gastos em educação obtidos nos balanços gerais do Governo do Estado do Acre. 
Gráfico 1: Percentual mínimo de vinculação e percentuais aplicados em MDE e em funções de despesa pública - 2001/2004-2013.

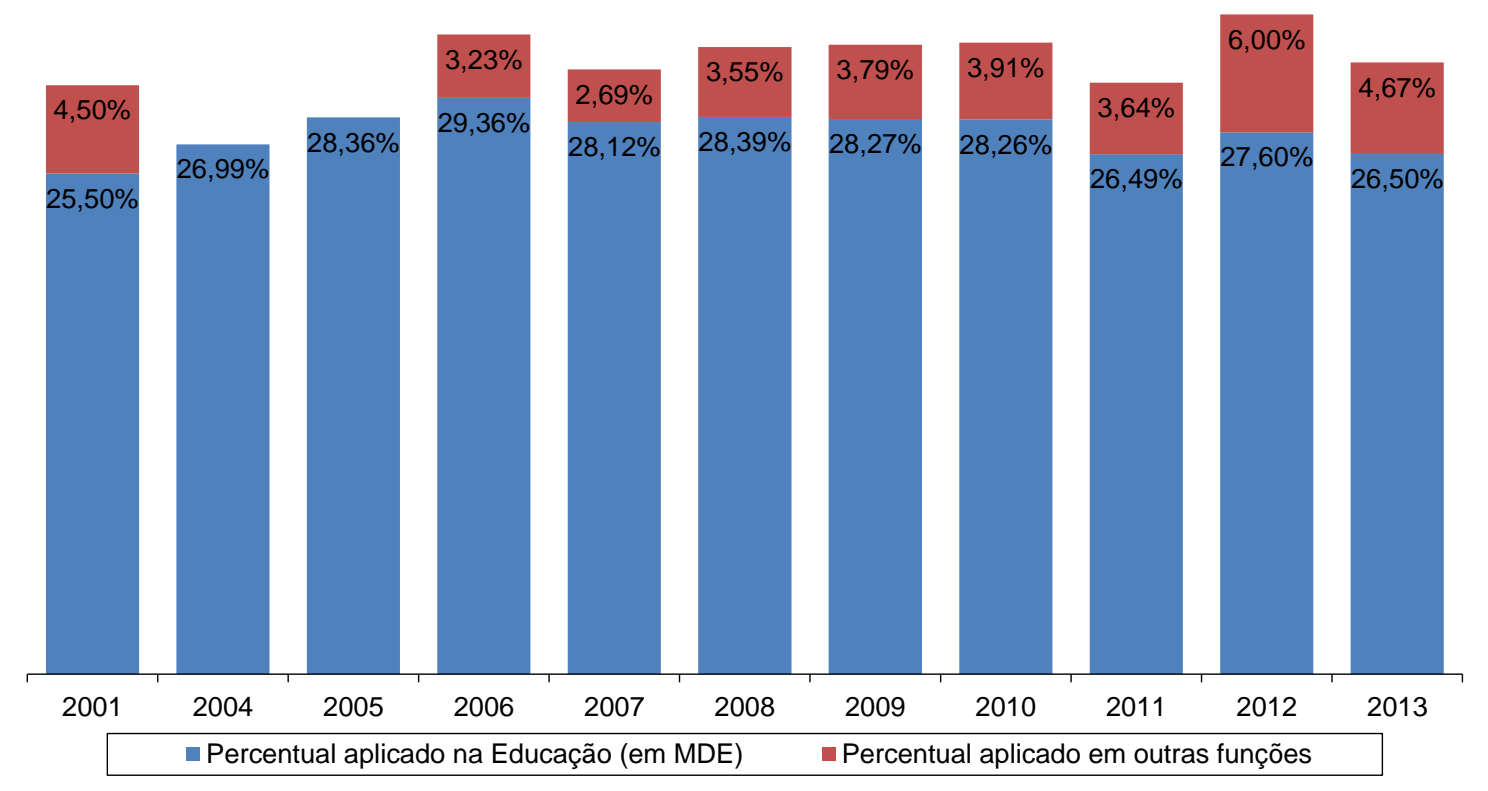

Fonte: Elaborado com base em Acre (2004; 2005; 2006; 2007; 2008; 2009; 2010; 2011; 2012; 2013).

Durante o período entre 2004 e 2013, a se confiar na contabilidade pública, o governo estadual cumpriu o que se entende ser a vinculação, assim como a aplicação em MDE, exceto para os anos de 2004 e 2005, sobre os quais não se dispõe de informação completa. Além disso, ele vem aplicando o percentual para gastos em outras funções. Somente em 2012 cumpriu a alíquota mínima para estas despesas. Na medida em que o TCE/AC se referencia na fiscalização da aplicação do percentual mínimo da CF88, os gastos tidos como educacionais nas outras funções parece não ser alvo de verificação, nem mesmo o $0,5 \%$ (meio por cento) a mais para MDE.

Pode-se afirmar que esse percentual é inócuo no seu objetivo. As despesas contempladas com a essa vinculação poderiam ser tratadas como prioridades orçamentárias em suas áreas específicas da mesma forma, não havendo dessa maneira a necessidade de atrelar tais despesas à função educação, portanto, esse procedimento não se justifica como forma de ampliação dos recursos.

De outra parte, a incorporação de despesas não estritamente educacionais na vinculação é estratégia similar e praticamente simultânea à implementada na Prefeitura do Município de São Paulo, um ano depois. Pode-se, por hipótese, supor que a alteração 
providenciada pelo Governo Estadual do Acre, pela sua antecedência, inspirou a mudança promovida na legislação paulistana estudada por Bassi (2015). Ou seja, sob um percentual superior ao piso estabelecido pela CF88, incluem-se e protegem-se, sob o manto da vinculação, despesas forçosa e impropriamente identificadas como educacionais. Ainda que possam ter a sua natureza e necessidade social protegidas não cabem, sob a justificativa da educação, no espírito de sua formulação nas constituições brasileira em que fora e é declarada, conforme discutido por Melchior (1984).

\section{Considerações finais}

A breve revisão sobre a vinculação das receitas de impostos e transferências para a educação nas constituições estaduais permitiu constatar que, para além do patamar mínimo estabelecido na CF88, as alterações implementadas, posteriormente, nas suas alíquotas, pelos governos estaduais, repercutiram nos contextos político-econômicos que se sucederam. Primeiro, no contexto da redemocratização brasileira dos anos 1980, as iniciativas estaduais que elevaram os percentuais acima do mínimo federal assim o fizeram na perspectiva de ampliação do acesso da população à educação escolar. Os anos 1990, as alterações que revisaram suas alíquotas para o patamar constitucional repercutiram o contexto de austeridade fiscal na reforma do estado, então preponderante, imposta pelo governo federal. No início dos anos 2000, ainda no contexto da política fiscal restritiva, os governos de oposição a esta orientação política e econômica, reinterpretaram a vinculação e ampliaram o seu escopo de cobertura para além da sua definição conceitual de aplicação dos recursos resultantes no ensino e na escola. Esse é o sentido da alteração da vinculação na Lei Orgânica do Município de São Paulo e na Constituição do Estado do Acre.

O arranjo legal introduzido na constituição acreana, em 2000, sob uma argumentação confusa, na verdade, eleva em apenas meio ponto percentual acima do mínimo constitucional federal a vinculação os recursos para a MDE. Destina 4,5\% (quatro e meio por cento) para despesas não educacionais, não relacionadas diretamente com o ensino. Pela sua antecedência, esse gesto parece ter sido precursor do que seria implementado em São Paulo em 2001. Sob o manto da elevação do percentual da vinculação, destinaram-se os novos recursos gerados para ações e atividades não educacionais, ou, pelo menos, não exatamente com o sentido originalmente estabelecido 
precipuamente de ensino, como definido na CF88 e na LDB. Ainda que as ações incluídas sejam legítimas e socialmente necessárias e até contribuam para a educação, o artifício desvia o sentido original de uma luta histórica na educação, qual seja vincular e proteger receitas para MDE.

Em tempos de esforços pela ampliação dos gastos em educação para $10 \%$ do percentual do PIB, na próxima década, como requer o cumprimento do atual PNE (BRASIL, 2013) para o cumprimento das metas estabelecidas, uma medida apropriada seria o Governo do Estado do Acre alterar a sua constituição e redefinir e reservar o atual percentual de vinculação especificamente para MDE. Desse modo, contribuiria efetivamente com um maior volume de recursos para atender as demandas de escolarização da sua população, ainda distante do atendimento adequado.

\section{REFERÊNCIAS}

ACRE. Balanço Geral do Acre. Análise da execução orçamentária, financeira e contábil do Balanço Geral do Estado do Acre 2004. Disponível em:

<http://www.ac.gov.br/wps/portal/acre/Acre/home>. Acesso em: 05 jul 2015.

ACRE. Balanço Geral do Acre. Análise da execução orçamentária, financeira e contábil do Balanço Geral do Estado do Acre 2005; 2006; 2007; 2008; 2009; 2010; 2011; 2012; 2013. Disponível em: 〈http://www.ac.gov.br/wps/portal/acre/Acre/home>. Acesso em: 05 jul 2015.

ACRE. Balanço Geral do Acre. Análise da execução orçamentária, financeira e contábil do Balanço Geral do Estado do Acre 2006; 2007; 2008; 2009; 2010; 2011; 2012; 2013. Disponível em: 〈http://www.ac.gov.br/wps/portal/acre/Acre/home〉. Acesso em: 05 jul 2015.

ACRE. Balanço Geral do Acre. Análise da execução orçamentária, financeira e contábil do Balanço Geral do Estado do Acre 2007; 2008; 2009; 2010; 2011; 2012; 2013. Disponível em: <http://www.ac.gov.br/wps/portal/acre/Acre/home>. Acesso em: 05 jul 2015.

ACRE. Balanço Geral do Acre. Análise da execução orçamentária, financeira e contábil do Balanço Geral do Estado do Acre 2008; 2009; 2010; 2011; 2012; 2013. Disponível em: <http://www.ac.gov.br/wps/portal/acre/Acre/home>. Acesso em: 05 jul 2015.

ACRE. Balanço Geral do Acre. Análise da execução orçamentária, financeira e contábil do Balanço Geral do Estado do Acre 2009; 2010; 2011; 2012; 2013. Disponível em: <http://www.ac.gov.br/wps/portal/acre/Acre/home>. Acesso em: 05 jul 2015. 
ACRE. Balanço Geral do Acre. Análise da execução orçamentária, financeira e contábil do Balanço Geral do Estado do Acre 2010; 2011; 2012; 2013. Disponível em: <http://www.ac.gov.br/wps/portal/acre/Acre/home>. Acesso em: 05 jul 2015.

ACRE. Balanço Geral do Acre. Análise da execução orçamentária, financeira e contábil do Balanço Geral do Estado do Acre 2011; 2012; 2013. Disponível em: <http://www.ac.gov.br/wps/portal/acre/Acre/home>. Acesso em: 05 jul 2015.

ACRE. Balanço Geral do Acre. Análise da execução orçamentária, financeira e contábil do Balanço Geral do Estado do Acre 2012; 2013. Disponível em: <http://www.ac.gov.br/wps/portal/acre/Acre/home>. Acesso em: 05 jul 2015.

ACRE. Balanço Geral do Acre. Análise da execução orçamentária, financeira e contábil do Balanço Geral do Estado do Acre 2013. Disponível em:

<http://www.ac.gov.br/wps/portal/acre/Acre/home>. Acesso em: 05 jul 2015.

ACRE. Constituição do Estado do Acre, de 3 de outubro de 1989. Disponível em: <www.al.ac.leg.br>. Acesso em: 06 fev 2012.

ACRE. Lei no 20/2000. Aumenta o investimento anual com Educação de $25 \%$ para 30\%. Modifica o Art. 197 da Constituição do Estado do Acre, 2000. Disponível em: <www.sinplac.net>. Acesso em: 06 fev 2012.

ACRE. Instrução Normativa no 06/2004. Disponível em: <www.sinplac.net>. Acesso em: 04 set 2013.

AMARAL, Nelson Cardoso. Para compreender o financiamento da educação básica no Brasil. Brasília: Liber Livro, 2012.

BASSI, Marcos Edgar. Os recursos financeiros aplicados na educação básica da rede de ensino da Prefeitura da cidade de São Paulo: subsídios para a construção de um plano de educação. Fineduca. Porto Alegre, vol. 1, n. 12, p. 1-20, 2011. Disponível em: <http://seer.ufrgs.br/index.php/fineduca/article/view/35799/25996>. Acesso em 10 jul. 2015.

BRASIL. Constituição da República Federativa do Brasil de 1988.Disponível em: <http://www.planalto.gov.br/ccivil_03/constituicao/constituicaocompilado.htm>. Acesso em: 11 jul. 2015.

BRASIL. Emenda Constitucional $\mathbf{n}^{\mathbf{0}}$ 14, de 12 de setembro de 1996. Modifica os arts. 34, 208, 211 e 212 da Constituição Federal e dá nova redação ao art. 60 do Ato das Disposições Constitucionais Transitórias. Disponível em: <http://www.planalto.gov.br/ccivil_03/constituicao/Emendas/Emc/emc14.htm>. Acesso em: 10 jul 2015.

BRASIL. Emenda Constitucional $\mathbf{n}^{\mathbf{0}}$ 53, de 19 dedezembro de 2006. Dá nova redação aos arts. $7^{\circ}, 23,30,206,208,211$ e 212 da Constituição Federal e ao art. 60 do Ato das Disposições Constitucionais Transitórias. Disponível em:

<http://www.planalto.gov.br/ccivil_03/constituicao/Emendas/Emc/emc53.htm>. Acesso em: 10 jul. 2015. 
BRASIL. Lei $\mathbf{n}^{\mathbf{0}} \mathbf{7 . 3 4 8}$, de 24 de julho de 1985. Dispõe sobre a execução do $\S 4^{\circ}$ do art. 176 da Constituição Federal, e dá outras providências. 1985. Disponível em: <http://www.planalto.gov.br/ccivil_03/LEIS/1980-1988/L7348.htm>. Acesso em: 08 jul. 2015.

BRASIL. Lei no 9.394, de 20 de dezembro de 1996.Estabelece as diretrizes e bases da educação nacional. 1996a. Disponível em:

<http://www.planalto.gov.br/CCIVIL_03/leis/L9394.htm>. Acesso em: 08 jul. 2015.

BRASIL. Lei no 9.424, de 24 de dezembro de 1996. Dispõe sobre o Fundo de Manutenção e Desenvolvimento do Ensino Fundamental e Valorização do Magistério. 1996b. Disponível em: <www.planalto.gov.br>. Acesso em: 06 fev. 2012.

BRASIL. Lei no 10.172, de 09 de janeiro de 2001. Aprova o Plano Nacional de Educação e dá outras providências. Disponível em: <www.planalto.gov.br〉. Acesso em: 06 fev. 2012.

BRASIL. Lei no 11.494, de junho de 2007. Regulamenta o Fundo de Manutenção e Desenvolvimento da Educação Básica e Valorização dos Profissionais da Educação. Disponível em: <www.planalto.gov.br>. Acesso em: 06 fev 2012.

BRASIL. Lei 13.005, de 25 de junho de 2013. Aprova o Plano Nacional de Educação PNE e dá outras providências. Disponível em: <http://www.planalto.gov.br/ccivil_03/_Ato2011-2014/2014/Lei/L13005.htm>. Acesso em 12 jul. 2015.

CASTRO, J. A de. Financiamento da Educação o Brasil. Em Aberto. Brasília, v. 18, n. 74, p. 11-32, 2001. Disponível em:

<http://emaberto.inep.gov.br/index.php/emaberto/issue/view/81>. Acesso em: 30 jun 2015.

CASTRO, J. A de. Financiamento e gasto público na educação básica no Brasil: 19952005. Educ. Soc., Campinas, v. 28, n. 100, p. 857-876, out/2007. Disponível em $<$ http://www.scielo.br/scielo.php?script=sci_arttext\&pid=S0101$73302007000300011 \& \operatorname{lng}=$ pt\&nrm=iso>. Acesso em: 01 jul. 2015. DOI: $<$ http://dx.doi.org/10.1590/S0101-73302007000300011>.

DAVIES, Nicholas. A confiabilidade dos órgãos de controle das verbas da educação. Em Aberto. Brasília, v. 28, n. 93, p. 131-143, jan./jun. 2015. Disponível em: <http://rbep.inep.gov.br/index.php/emaberto/article/viewFile/3724/2200>. Acesso em: 09 jul. 2015.

DAVIES, Nicholas. Os Tribunais de Contas do Acre, Amapá, Amazonas, Rondônia, Roraima e Tocantins e seus procedimentos de contabilização da receita e despesa em educação. HISTEDBR. Campinas, v.12, n. 45, p. 200-222, mar. 2012. Disponível em: <https://www.fe.unicamp.br/revistas/ged/histedbr/article/view/3082>. Acesso em: 10 jul. 2015.

DAVIES, Nicholas. A frágil confiabilidade do tribunal de contas de Santa Catarina na fiscalização dos recursos da educação: [...]. Perspectiva. Florianópolis, v. 29, n. 1, p. 
193- 226, jan./jun. 2011. Disponível em:

<https://periodicos.ufsc.br/index.php/perspectiva/article/viewFile/2175-

795X.2011v29n1p193/19418>. Acesso em: 09 jul. 2015.

DAVIES, Nicholas. Educação \& Sociedade. Campinas, v. 31, n. 110, p. 93-111, jan./mar. 2010. Disponível em: <http://www.scielo.br/pdf/es/v31n110/06.pdf>. Acesso em: 09 jul. 2015.

DAVIES, Nicholas. Aplicação dos recursos vinculados à educação: a verificação do Tribunal de contas do Mato Grosso do Sul. RBPE. Brasília, v. 88, n. 219, p. 345-362, maio/ago. 2007. Disponível em:

<http://rbep.inep.gov.br/index.php/RBEP/article/view/502>. Acesso em: 09 jul. 2015.

DAVIES, Nicholas. Financiamento da educação: novos ou velhos desafios? São Paulo: Xamã, 2004a.

DAVIES, Nicholas. O financiamento da educação e seus desafios. Eccos. São Paulo, v. 6, n. 1, p. 43-63, jun., 2004b. Disponível em:

<http://www4.uninove.br/ojs/index.php/eccos/article/view/367>. Acesso em: 09 jul. 2015.

DAVIES, Nicholas. O financiamento da educação estatal no Brasil: velhos e novos desafios. RBPAE, v. 16, n. 2, p. 159-176, jul./dez, 2000. Disponível em:

<http://seer.ufrgs.br/index.php/rbpae/article/view/25795/15068>. Acesso em: 09 jul. 2015.

DAVIES, Nicholas. Tribunal de Contas: faz as contas ou faz-de-conta na avaliação dos gastos governamentais com educação? RBEP, Brasília, v. 80, n. 194, p. 19-27, jan./abr. 1999. Disponível em:

<http://emaberto.inep.gov.br/index.php/RBEP/article/viewFile/194/195>. Acesso em: 09 jul. 2015.

FÁVERO, Osmar. (Org.). A educação nas constituintes brasileiras 1823-1988. 3. ed. Campinas, SP: Autores Associados, 2005. (Coleção memória da educação).

GOIÁS. Constituição do Estado de Goiás, de 05 de outubro de 1989. Disponível em: <http://www.gabinetecivil.goias.gov.br/constituicoes/constituicao_1988.htm>. Acesso em: 08 jul 2015.

GOMES, Candido Alberto et al. O financiamento da educação brasileira: uma revisão da literatura. RBPAE. Disponível em:

<http://seer.ufrgs.br/rbpae/article/viewFile/19012/11043>.

Acesso em: 08 jul 2015.

MATO GROSSO DO SUL. Constituição do Estado do Mato Grosso do Sul, de 5 de outubro de 1989. Disponível em:

<http://www.al.ms.gov.br/LinkClick.aspx?fileticket=vY9Gt9a1ypw\%3D\&tabid=220>. Acesso em: 08 jul 2015.

MELCHIOR, José Carlos de Araújo. A vinculação constitucional de recursos

financeiros para a educação: esfera federal. Cadernos de Pesquisa. São Paulo, p. 15- 
21, ago. 1984. Disponível em:

<http://publicacoes.fcc.org.br/ojs/index.php/cp/article/view/1443/1438>. Acesso em: 30 jun. 2015.

O MANIFESTO dos Pioneiros da Educação Nova. Histdebr. Campinas, $\mathrm{n}^{\mathbf{o}}$ especial, ago. 2006. Disponível em

<http://www.histedbr.fe.unicamp.br/revista/edicoes/22e/doc1_22e.pdf>. Acesso em: 08 jul. 2015.

OLIVEIRA, Romualdo Portela de. O financiamento público da educação e seus problemas. In OLIVEIRA, Romualdo Portela de (org.). Política educacional. Impasses e alternativas. São Paulo: Cortez, 1995, p. 124-144.

OLIVEIRA, Romualdo Portela de. O financiamento da educação. In: OLIVEIRA, Romualdo Portela de.; ADRIÃO, T. (Orgs.). Gestão, Financiamento e Direito à Educação: análise da Constituição Federal e da LDB. 3ed. São Paulo: Xamã, 2001.

OLIVEIRA, Romualdo Portela de.; CATANI, Afrânio Mendes. Constituições estaduais brasileiras e educação. São Paulo: Cortez, 1993.

OLIVEIRA, Romualdo Portela de.; ADRIÃO, Theresa. Noções gerais sobre o financiamento da educação no Brasil. Eccos. São Paulo, v. 8, n. 1, p. 23-46, jan./jun. 2006. Disponível em:

<http://www.uninove.br/pdfs/publicacoes/eccos/eccos_v8n1/eccos_v8n1.pdf >. Acesso em: 06 jul. 2015.

SENA, Paulo. A União e a aplicação dos recursos vinculação à manutenção e ao desenvolvimento do ensino. RBPE. Brasília, v. 83, n. 203/204/205, p. 7-22, jan./dez. 2002. Disponível em:

<http://rbep.inep.gov.br/index.php/RBEP/article/viewFile/118/120>. Acesso em: 09 jul. 2015.

TRIBUNAL DE CONTAS DO ESTADO DO ACRE. Resolução no 33, de 30 de março de 2000. Dispõe sobre a fiscalização exercida pelo Tribunal de Contas do Estado sobre a aplicação dos recursos constitucionalmente destinados à manutenção e ao desenvolvimento do ensino no Estado do Acre. 2000. Disponível em: <http://www.tce.ac.gov.br/portal/jdownloads/LEGISLAO/Resolues/resoluo_033__2000.pdf>. Acesso em: 12 jul. 2015.

VELloso, Jaques. A emenda Calmon e os recursos da União. Cadernos de Pesquisa. vol. 74, p. 20-39, agosto, 1990. 


\section{Como referenciar este artigo}

BASSI, Marcos Edgar; VERÇOSA, Pelegrino Santos. O financiamento da educação básica no estado do Acre/BR: um estudo da vinculação da receita de impostos. Revista on line de Política e Gestão Educacional, Araraquara, v.21, n.2, p. 303-321, maio/ago. 2017. Disponível em: <http://dx.doi.org/10.22633/rpge.v21.n.2.2017.9951>. ISSN: 1519-9029.

Submetido em: 07/06/2017

Aprovado em: 26/07/2017 